\title{
Carcinoma of the colon presenting with dyspepsia
}

\author{
D. O'Reilly and R.G. Long
}

City Hospital, Hucknall Road, Nottingham NG5 1PB, UK.

\begin{abstract}
Summary: Three patients with upper abdominal symptoms responding to anti-ulcer medication are reported who had negative upper gastrointestinal endoscopies. Subsequent barium enemas showed that each of the patients had either a carcinoma of the transverse colon or caecum. Investigation of the colon should be considered in all such cases.
\end{abstract}

\section{Introduction}

Gastroscopy is now the investigation of choice in patients with upper gastrointestinal tract symptoms. If it is negative, imaging of the gallbladder may be indicated. If this is also negative, many patients are rightly labelled as having functional dyspepsia and fit into the group of up to $44 \%$ of patients attending a gastroenterology clinic who have no organic diagnosis. ${ }^{1}$ In 18 months 3 patients with dyspeptic symptoms referred to one clinic have subsequently been shown to have carcinoma of the colon.

\section{Case reports (Table I)}

\section{Case 1}

A 31 year old barman had heartburn and epigastric pain waking him at night. Carbenoxolone had effectively treated similar symptoms 6 months before but was now ineffective. He had lost seven pounds. Five years earlier a duodenal ulcer was diagnosed by barium meal after a haematemesis. His bowel habit was normal. On examination he was tender in the epigastrium. The haemoglobin was $11.6 \mathrm{~g} / \mathrm{dl}$ with a microcytic hypochromic film and the erythrocyte sedimentation rate (ESR) was $30 \mathrm{~mm} /$ hour. A clinical diagnosis of duodenal ulcer was made but gastroscopy was normal. In view of the iron deficiency a barium enema was requested and this showed a carcinoma of the ascending colon.

\section{Case 2}

A 67 year old male retired civil servant had a 5-week history of constant pain in the left hypochondrium which radiated through to the back. The pain was

Correspondence: R.G. Long M.D., M.R.C.P.

Accepted: 23 September 1986 relieved by food and Gaviscon. There was no weight loss or change in bowel habit. Examination was normal. Sigmoidoscopy revealed a small adenomatous polyp at $5 \mathrm{~cm}$. The haemoglobin was $15.4 \mathrm{~g} / \mathrm{dl}$ and the ESR was $23 \mathrm{~mm} / \mathrm{h}$. A peptic ulcer was thought likely but gastroscopy was normal. A barium enema was performed because of the polyp and a carcinoma of the transverse colon was found.

\section{Case 3}

A 54 year old male clerk was referred 4 weeks after the sudden onset of severe epigastric pain and vomiting. $\mathrm{He}$ also had retrosternal burning discomfort. Antacids had no effect but the pain settled with cimetidine. There was no history of weight loss or change of bowel habit. Examination was normal apart from anaemia. $\mathrm{He}$ had a microcytic hypochromic anaemia of $6.8 \mathrm{~g} / \mathrm{dl}$ and an ESR of $27 \mathrm{~mm} / \mathrm{h}$. A peptic ulcer was suspected but gastroscopy was normal. A barium enema was performed because of the iron deficiency and showed a carcinoma of the transverse colon.

\section{Discussion}

All these men had upper abdominal pain with symptomatic relief from ulcer healing agents. None had lower bowel or abdominal symptoms. An early barium enema was performed in two cases because of unexplained iron deficiency, and in one because of the chance finding of a rectal polyp. A delay in diagnosis would probably have worsened the prognosis.

Up to $40 \%$ of patients with colorectal carcinoma may have abdominal pain as a presenting symptom. ${ }^{2}$ The site of the pain can be explained by the observation that balloon distension of the right sided colon reliably referred pain to the upper abdomen. ${ }^{3}$ It is difficult to explain how the anti-ulcer drugs helped the 
pain; possible explanations include a placebo effect on colonic pain or coexistent peptic ulceration. Another study of patients with chronic abdominal pain found that distension proximal to the splenic flexure referred pain to the midline and to the right of both the upper and lower abdomen. ${ }^{4}$ Distal to the splenic flexure pain was referred to the lower midline and left iliac fossa.

Cook et $a l .^{5}$ have recently stressed the need to investigate the colon in elderly patients with an iron deficiency anaemia when the upper gastrointestinal endoscopy is either normal or shows only benign lesions. They prospectively studied 100 patients of mean age 70 with an iron deficiency anaemia and found 14 patients with a total of 15 colorectal cancers and 6 patients with 22 adenomatous polyps greater than $1 \mathrm{~cm}$. Three patients with colonic carcinoma had upper gastrointestinal symptoms but it is not stated whether these were some of the several patients who also had gastro-oesophageal lesions. Our data woulc suggest that colorectal investigation should be con:sidered in less elderly iron deficient patients as Case was only 31 .

It should be remembered that colonic lesions mayo refer pain to any site in the abdomen, the back and chest. Pain in the upper abdomen does not imply and 'upper gut' lesion. Colorectal carcinoma is a commono disorder which caused 16,583 deaths in the UK in" England and Wales in $1983 .{ }^{6}$ It should be considered in $\vec{P}$ the differential diagnosis of abdominal pain in all $\angle$ patients over 30 . In patients with unexplained iron deficiency or adenomatous polyps on sigmoidoscopy응 colorectal investigation would seem mandatory.

Table I Summary of clinical data in 3 patients with carcinoma of the colon

\begin{tabular}{|c|c|c|c|c|c|c|c|}
\hline Patient & $\begin{array}{c}\text { Relief antacids/ } \\
\text { ulcer healing drugs }\end{array}$ & $\begin{array}{l}\text { History } \\
\text { of ulcer }\end{array}$ & Weight loss & Sigmoidoscopy & $\begin{array}{c}\text { Iron } \\
\text { deficiency }\end{array}$ & $\begin{array}{l}\text { Site of } \\
\text { tumour }\end{array}$ & Duke's stage \\
\hline 1 & Yes & Yes & Yes & - & Yes & Caecum & $\mathbf{B}$ \\
\hline 2 & Yes & No & No & Polyp & No & $\begin{array}{l}\text { Transverse } \\
\text { colon }\end{array}$ & B \\
\hline 3 & Yes & No & No & - & Yes & $\begin{array}{c}\text { Transverse } \\
\text { colon }\end{array}$ & 'D' \\
\hline
\end{tabular}

\section{References}

1. Harvey, R.F., Salih, S.Y. \& Read, A.E. Organic and functional disorders in 200 gastroenterology outpatient referrals. Lancet 1983 , i: $632-634$.

2. Edwards, R.T.M. \& Bransom, C.J. Presentation of colorectal carcinoma. Lancet 1983, i: 1285.

3. Kingham, J.G.C. \& Dawson, A.M. Origin of chronic right upper quadrant paint. Gut, 26, 783-788.

4. Swarbrick, E.T., Hegarty, J.E., Bat, L. Williams, C.B. \& 